T-CELL RESPONSES

\section{Selective memory}

Although it has long been appreciated that heterogeneity exists within the memory T-cell pool, little is known of the developmental relationship between different memorycell s ubsets or their functional significance. A new study in the April issue of Nature Medicine, which examines $\mathrm{CD}^{+}$memory T-cell subsets in different human infections, reveals virus-specific patterns of memorycell heterogeneity.

Appay et al. analysed the $\mathrm{CD} 8^{+}$ memory T-cell subsets that are present during four persistent human viral infections - HIV-1, hepatitis C virus (HCV), Epstein-Barr virus (EBV) and cytomegalovirus (CMV). Antibodies specific for the T-cell differentiation markers CD27 and $\mathrm{CD} 28$ were used in conjunction with peptide-MHC tetramers to classify antigen-specific $\mathrm{T}$ cells by flow cytometry. CD27 and CD28 are useful markers because once their expression is lost, there is no evidence of re-expression, unlike some memory markers that are commonly used. Three T-cell subsets can be defined on this basis, which are proposed to represent distinct stages along the differentiation pathway $\mathrm{CD} 27^{+} \mathrm{CD} 28^{+}$(early), $\mathrm{CD} 27^{+} \mathrm{CD} 28^{-}$ (intermediate) and $\mathrm{CD} 27^{-} \mathrm{CD} 28^{-}$ (late) memory T cells.

During the acute phase of HIV-1, $\mathrm{HCV}$ and EBV infection, little variation in antigen-specific $\mathrm{CD} 8^{+} \mathrm{T}$-cell phenotype was found between infections; there was a large number of $\mathrm{CD} 27^{+} \mathrm{CD} 28^{+}$antigen-specific $\mathrm{T}$ cells that expressed low levels of the cytotoxic molecule perforin. Later, virusspecific profiles of memory $\mathrm{T}$ cells emerged. For EBV and HCV infection, memory T cells of the 'early' phenotype were enriched, whereas for CMV infection, $\mathrm{T}$ cells of the 'late' phenotype dominated. By contrast, for HIV-1 infection, 'intermediate' memory $\mathrm{T}$ cells were enriched.

But, what are the functional differences between the different memory subsets? The authors found an increase in cytotoxic potential that was associated with a decrease in proliferative capacity as memory $\mathrm{T}$ cells progressed from 'early' to 'late' stages (see diagram).

It is not known why infection with different viruses results in different profiles of memory $\mathrm{T}$ cells - antigen load and dispersal, viral evasion mechanisms or viral influence on the cytokine environment are all potential factors, and discriminating between these will be an important avenue for future research.

Jennifer Bell

(2) References and links ORIGINAL RESEARCH PAPER Appay, V. etal. Memory $C D 8^{+} T$ cells vary in differentiation phenotype in different persistent virus infections. Nature Med. 8, 379-385 (2002)

FURTHER READING Klenerman, P., Cerundolo, V. \& Dunbar, P. R. Tracking T cells with tetramers: new tales from new tools. Nature Rev. Immunol. 2, 263-272 (2002)

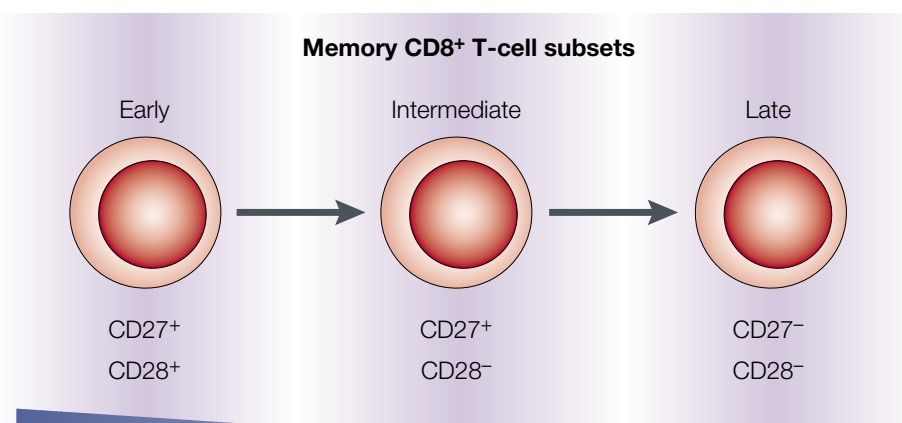

Proliferative capacity

\section{IN BRIEF}

\author{
IMMUNE THERAPY
}

Down-regulation of diabetogenic $\mathrm{CD}^{+} \mathrm{T}$ cells by a soluble dimeric peptide-MHC-class-II chimera.

Casares, S. et al. Nature Immunol. 25 February 2002 (DOl 10.1038/ni770)

The short half-life of peptides in vivo limits their efficacy in specific immunotherapy, but soluble petide-MHC dimers might provide a solution. In this study, peptide-MHC-class-II dimers were tested in a mouse model of diabetes. Mice that were doubly transgenic for the model antigen hemagglutinin (HA) driven by the insulin promoter and an MHC-class-II-restricted HA-specific TCR developed diabetes spontaneously. But, the injection of HA-peptide-MHC dimers prevented disease onset and limited the severity of established disease. The peptide-MHC dimers seem to work by anergizing splenic $\mathrm{T}$ cells and stimulating the formation of IL-10-secreting regulatory $T$ cells in the pancreas.

\section{VACCINES}

Anti-4-1BB scFv for gene therapy of cancer.

Ye, Z. et al. Nature Med. 8, 343-348 (2002)

With the exception of melanomas, vaccination against human cancer has yielded disappointing results. One promising approach, which used antibodies that are specific for the T-cell co-stimulatory molecule 4-1BB, caused the regression of subcutaneous tumours. In this study, the variable regions of anti-4-1BB antibodies were transfected into, and expressed on the surface of, the mouse melanoma cell line K1735. Although K1735 is poorly immunogenic, the transfected cell line induced a strong T-helper 1 response, for which $\mathrm{CD} 4^{+} \mathrm{T}$ cells and natural killer cells were required, and immunized mice were able to reject tumours that were growing subcutaneously or in the lungs.

\section{IMMUNE REGULATION}

Involvement of receptor-interacting protein 2 in innate and adaptive immune responses.

Chin, A. I. et al. Nature 416, 190-194 (2002)

RICK/Rip2/CARDIAK mediates signalling for receptors of the innate and adaptive immune systems.

Kobayashi, K. et al. Nature 416, 194-199 (2002)

Innate and adaptive immune responses contribute to host defence against pathogens. Innate immunity acts through Tolllike receptors (TLRs) and adaptive immunity acts through antigen-specific receptors. These papers show, by genetic targeting, that the caspase-recruitment domain (CARD)containing serine/threonine kinase Rip2 (also known as RICK and CARDIAK) transduces signals for both the innate and adaptive immune systems. Rip $2^{-1-}$ mice had defective immune responses downstream of TLRs and Nod proteins (molecules that are also implicated in the innate response), as well as impaired differentiation, cytokine production, activation and proliferation of T-helper 1 cells. 